\title{
Development of a balloon-style pressure vessel for GRAINE balloon-borne experiment in 2015
}

\author{
Hiroki Rokujo* and Naoto Otsuka \\ Nagoya University \\ E-mail: rokujodflab.phys.nagoya-u.ac.jp \\ for the GRAINE collaboration \\ Aichi University of education, ISAS/JAXA, Kobe University, Nagoya University, Okayama \\ University of science, Utsunomiya University
}

\begin{abstract}
Gamma-Ray Astro-Imager with Nuclear Emulsion (GRAINE) is a cosmic gamma- ray observation project that uses a balloon-borne emulsion detector. The angular resolution of the emulsion gamma-ray telescope $\left(0.08^{\circ} @ 1-2 \mathrm{GeV}\right)$ is one order of magnitude higher than that of the FermiLAT. In addition, it is sensitive to gamma-ray polarization. GRAINE aims at high-resolution imaging of SNRs and point sources in the Galactic plane/center, and the polarimetry in the unexplored sub-GeV/GeV region, by long duration balloon flights with large aperture area telescopes $\left(\sim 10 \mathrm{~m}^{2}\right)$. In 2015 May, the second GRAINE balloon-borne experiment was conducted in Australia to detect the well-known bright gamma-ray source, Vela pulsar, and to demonstrate the performance of the emulsion telescope. The aperture area was $3780 \mathrm{~cm}^{2}$ and the flight duration was $\sim 14$ hours. We adopted and developed a balloon-style pressure vessel for GRAINE 2015. The entire emulsion telescope was contained in a pressure vessel pressurized to $\sim 0.3 \mathrm{~atm}$ in differential pressure to maintain the vacuum-packed emulsion chamber at balloon altitudes. It consists of aluminum rings, two hemispherical rubber films, and shells made of plastic fabric, which reduces the absorbance of signals, and the backgrounds caused by cosmic ray interactions at the surface of the vessel. We report the balloon-style pressure vessel and the flight performance in the GRAINE balloon- borne experiment in 2015.
\end{abstract}

The 34th International Cosmic Ray Conference

30 July- 6 August, 2015

The Hague, The Netherlands

\footnotetext{
* Speaker.
} 


\section{Introduction}

Gamma-Ray Astro Imager with Nuclear Emulsion (GRAINE) is a cosmic gamma-ray observation project that uses a balloon-born emulsion detector [四[]. The angular resolution of the emulsion gamma-ray telescope, $0.08^{\circ} @ 1-2 \mathrm{GeV}$, is one order of magnitude higher than that of the Fermi-LAT [B]]. In addition, it is sensitive to gamma-ray polarization. GRAINE aims at highresolution imaging of SNRs and point sources in the Galactic plane/center, and the polarimetry in the unexplored sub-GeV/GeV region, by long duration balloon flights $(\sim 200$ hours) with large aperture area telescopes $\left(\sim 10 \mathrm{~m}^{2}\right)$.

The emulsion telescope consists of the converter, the time stamper, and the calorimeter. $\mathrm{Nu}$ clear emulsion films, a 3D high resolution tracking detector with sub-micron and milli-radian resolution, are employed for all components. The converter (100 sets of interleaved emulsion film) detects $\gamma \rightarrow \mathrm{e}^{+}+\mathrm{e}^{-}$events, and reconstructs incident angles of gamma-rays by the precise measurements at the starting points of each track angle. The time stamper based on the "emulsion multistage shifter" technique [䧃][回] is set at the down stream. During the observation period, multi-stage shifter moves multiple emulsion films cyclically like an analog clock. After the observation, we can reconstruct arrival time of each event with sub-second resolution by analyzing position displacements induced intentionally between tracks recorded in the shifter films. The calorimeter (several dozen sets of an emulsion film and metal plates), at the bottom of the telescope, measures momentum of tracks via the multiple coulomb scattering method [ 6$]$. In order to monitor the attitudes of the telescope toward the celestial coordinates, multiple star cameras are mounted on the gondola in distinct directions.

This paper describes development of a pressure vessel for the GRAINE balloon experiment, which was performed in 2015 May, and the flight performance.

\section{Balloon-style pressure vessel for GRAINE 2015}

\subsection{Design of GRAINE 2015}

In the first balloon experiment, GRAINE 2011, the technical feasibility was demonstrated by a small-scale emulsion telescope and a star camera system []. The second experiment, GRAINE 2015, aims at detecting a gamma-ray source, and demonstrating the imaging performance of the emulsion telescope in the $100 \mathrm{MeV}$ energy region. By a middle duration balloon flight (12-24 hours) in Alice Springs, Australia, observation of the Vela pulsar, the brightest gamma-ray source in the sub-GeV/GeV gamma-ray sky, for 6.5 hours (within the field of view of the emulsion telescope) is expected. We enlarged the aperture area of the second telescope to $3780 \mathrm{~cm}^{2}$, which is 29 times larger than that of the first telescope, and designed it for 5 sigma detection of the Vela pulsar, according to gamma-ray flux of the Vela pulsar in the Fermi-LAT catalogue [ $[$ ] $]$.

\subsection{Balloon-style pressure vessel}

We introduced a pressure vessel to GRAINE 2015 to maintain the vacuum-packed emulsion chambers at balloon altitudes. The vacuum-packed chamber offers the following advantages: preventing deformation of the converter in a severe environment with the temperature variation; keeping humidity around films low and preventing the fading effect in case of long time taken for a re- 
covery; and, shading and waterproofing to ensure recovery. The pressure vessel for GRAINE 2015 is required to keep the inner pressure above $100 \mathrm{hPa}$ during the observation period at level flight (the residual atmospheric pressure at this altitude is $4-5 \mathrm{hPa}$ ). Moreover, thickness and material of the vessel prefer thin and low-Z respectively, which reduce the absorbance of signal gamma-rays, and the production of background gamma-rays caused by cosmic ray interactions at the surface of the vessel.

We developed a "balloon-style" pressure vessel, of which the ATIC group adopted the concept $[\mathbb{[}]$. Figure $\mathrm{U}$ and $\square$ show a picture of the balloon-style pressure vessel and its cross sectional view, respectively. The main ring is a $1.6 \mathrm{~m}$-diameter ring that is formed by curving two $\mathrm{C}$-shaped aluminum channels and welding them. The emulsion telescope is fixed inside the main ring. The sub ring is made from two L-shaped aluminum angles with the same process as the main ring. An airtight hemispheric film is put between the main ring and the sub ring with packing. A natural rubber balloon (COSMOPRENE made by the Weather Balloon Mfg. Co., Ltd.), which is employed to meteorological observation, is cut up in half and used for it. The thickness is $0.3 \mathrm{~mm}$. The silicon tube functions as the packing. By squashing the long tube running twice along the ring, enough conductance is gained with no groove at the main and sub rings. Four aluminum wings are welded to the side of the main ring. The vessel is hanged at their end points so that a shock at launching doesn't reach to the ring.

The hemispheric shells are fixed at the sub rings with enveloping the rubber films. From Laplace's equation, surface tension $T$ at a sphere is written as

$$
T=\frac{1}{2}\left(P_{\text {in }}-P_{\text {ext }}\right) R=\frac{1}{2} \Delta P R
$$

where $R$ is radius of a sphere, $P_{i n}$ and $P_{\text {ext }}$ are internal pressure and external pressure, respectively, and $\Delta P$ is differential pressure. When $R$ and $\Delta P$ are $0.8 \mathrm{~m}$ and $300 \mathrm{hPa}$ respectively, $T$ is 120 $\mathrm{N} / \mathrm{cm}$. For the material of the hemispheric shell, polyester fabric coated with polyvinyl chloride (PVC-PES fabric made by Taiyo Kogyo Corporation) is selected. Its thickness and weight are 0.7 $\mathrm{mm}$ and $0.095 \mathrm{~g} / \mathrm{cm}^{2}$, respectively. PVC-PES fabric is appropriate for molding various shapes by welding. In addition, it is tolerant of bending, so careless handing causes no possibility of break. The tensile strength is $2904 \mathrm{~N} / 3 \mathrm{~cm}(=968 \mathrm{~N} / \mathrm{cm})$. The elongation percentage is $3 \%$, when the load is $120 \mathrm{~N} / \mathrm{cm}$. In a $-70{ }^{\circ} \mathrm{C}$ environment, the tensile strength of the material is steady, and there is no peeling at weld.

In an observation period, $\Delta P$ and $T$ increase with ascending the balloon $\left(P_{\text {ext }}\right.$ decreases from $\sim 1013 \mathrm{hPa}$ to $\sim 5 \mathrm{hPa}$ ). To protect the fabric shells, a relief valve (made by Circle Seal Controls) is jointed at the main ring. When $\Delta P$ is over its cracking pressure $280-300 \mathrm{hPa}$ (changeable), the inner air escapes outside.

The total weight including rings, trusses, and hemispheres is $140 \mathrm{~kg}$. The dimension is $\mathrm{W} 2.4$ $\mathrm{m} \times \mathrm{D} 2.4 \mathrm{~m} \times \mathrm{H} 1.9 \mathrm{~m}$.

\subsection{Leakage check test on the ground}

We evaluated the overall leakage of the vessel. Tests were performed in a constant temperature chamber. Under $P_{e x t} \sim 1 \mathrm{~atm}$, the atmospheric pressure on the ground, air was injected into the vessel by an air compressor, then changes in $\Delta P$ from $300 \mathrm{hPa}$ were measured at three temperatures, $20^{\circ} \mathrm{C},-30^{\circ} \mathrm{C}$, and $-40^{\circ} \mathrm{C}$. 


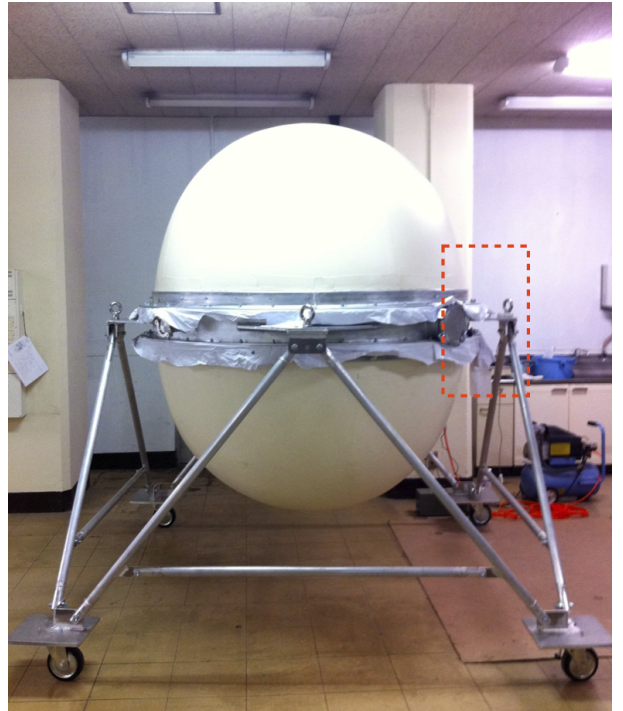

Figure 1: Picture of balloon-style pressure vessel. Cross sectional view at the part indicated by red square is shown in Figure 2

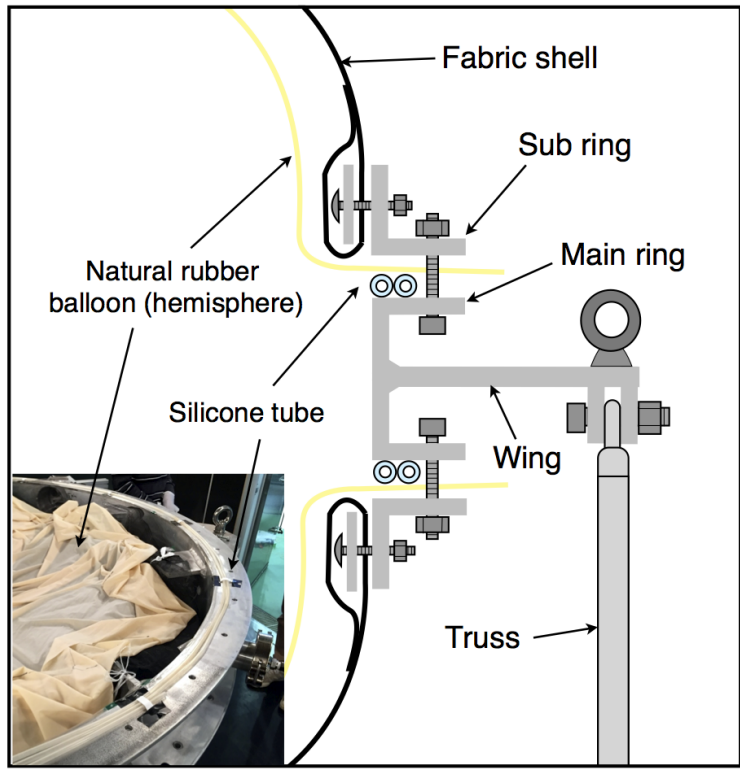

Figure 2: Cross sectional view at main ring and sub rings

Figure [ 3 shows measured pressures. $\Delta P(t)$ indicates an exponential decrease, which expresses the following equation.

$$
\Delta P(t)=\Delta P(0) e^{-C t} \quad(C=0.0053)
$$

Leakage conductance $C$ is constant (it depends on the size of an air passage). $\Delta P$ keeps above $100 \mathrm{hPa}$ for more than 24 hours. Its performance doesn't change also at the low-temperature environments.

In Figure [1, magenta plot shows the measurement just before the balloon launching of GRAINE 2015. $\Delta P$ is winding because of diurnal fluctuations in temperature, but the global component was consistent with results in the environmental tests. During level flight, $P_{i n}$ is not $\sim 1300 \mathrm{hPa}$ but $\sim 300 \mathrm{hPa}$. Therefore, the effect cased by temperature is slighter.

\section{Performance in balloon flight}

\subsection{Balloon flight}

All detectors were assembled on the gondola at Balloon Launching Station (BLS) in Alice Springs, Australia. Figure tha shows a picture of setup inside the vessel. Emulsion films were stacked, and packed with laminated polyethylene bags in the vacuum chamber (blow $10 \mathrm{hPa}$ ). Then the emulsion chambers were fixed on the multi-stage shifter. The pressurized vessel was wrapped with insulating materials as figure thb.

The GRAINE 2015 balloon-borne experiment was performed on May 12th [Q][एँ]. The balloon carrying the gondola was launched at 6:33 Australian Central Standard Time (ACST) from 


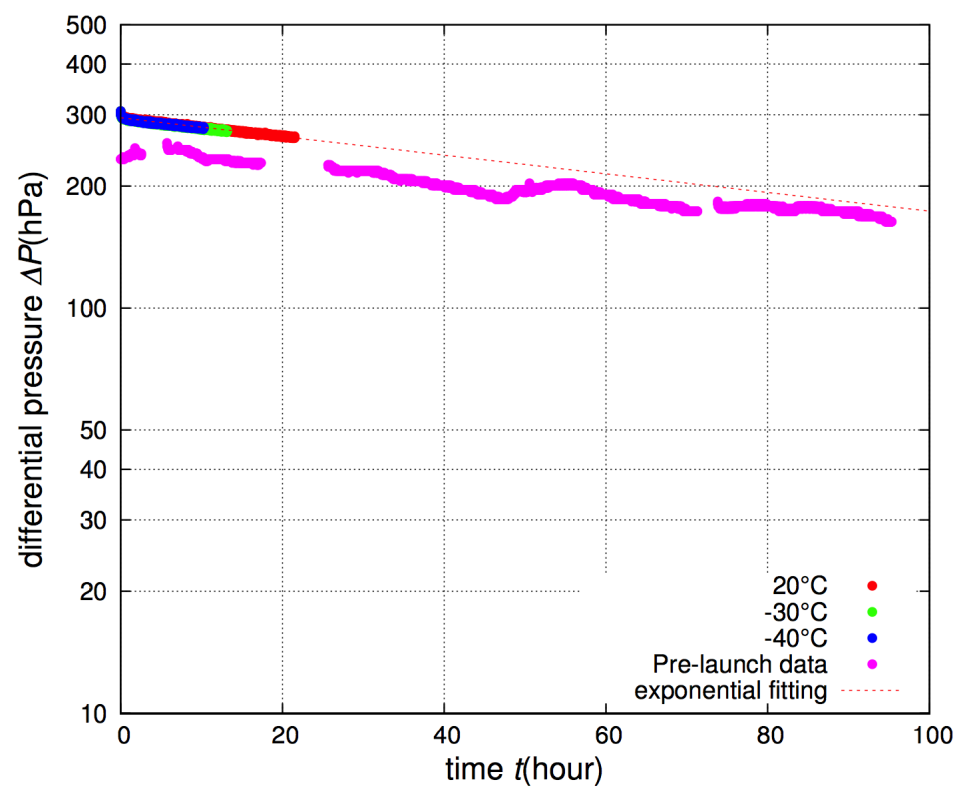

Figure 3: Results of leakage check test on the ground. Red, green, and blue plots are the measurements in the constant temperature chamber at $20^{\circ} \mathrm{C},-30^{\circ} \mathrm{C}$, and $-40^{\circ} \mathrm{C}$, respectively. Magenta plot is the measurement just before the balloon launching of GRAINE 2015.

BLS (figure Ac). It ascended, and reached at altitude of $37.2 \mathrm{~km}$ at 8:50 ACST. The emulsion telescope floated to the west for 11.5 hours. Its system turned off at 20:02 ACST. 20 minutes after that, the gondola was cut down. At 20:55 ACST, the gondola fell on the ground about $130 \mathrm{~km}$ north of Longreach in Queensland. The emulsion films and the other detectors were safely recovered the next day.

\subsection{Result}

Figure 1 shows inner pressure $P_{\text {in }}$ (red), external pressure $P_{\text {ext }}$ (blue), and temperature at the bottom of the PVC-PES fabric shell (green). After launching, $P_{\text {ext }}$ decreased with the ascent of the balloon. When $\Delta P$ reached $280 \mathrm{hPa}, P_{\text {in }}$ also started following. Then, at level fight $P_{\text {in }}$ became stable as well as $P_{\text {ext }}$. These acts of pressures confirmed that opening and closing of the relief valve worked correctly in the flight. Changes in $P_{i n}$ after the sunset were consistent with decrease in temperature. In the GRAINE 2015 balloon-borne experiment, the pressure inside the vessel was kept above $240 \mathrm{hPa}$ during level flight.

\section{Conclusion and prospect}

The balloon-style pressure vessel was developed for GRAINE 2015 balloon-borne experiment. Polyester fabric coated with polyvinyl chloride and natural rubber were adopted as the material of the hemispheric shells. The mass at the top of the vessel was reduced to $0.1 \mathrm{~g} / \mathrm{cm}^{2}$ from $0.54 \mathrm{~g} / \mathrm{cm}^{2}$, in case of a $2 \mathrm{~mm}$-thick aluminum vessel. In the whole balloon flight, the expected operation was 


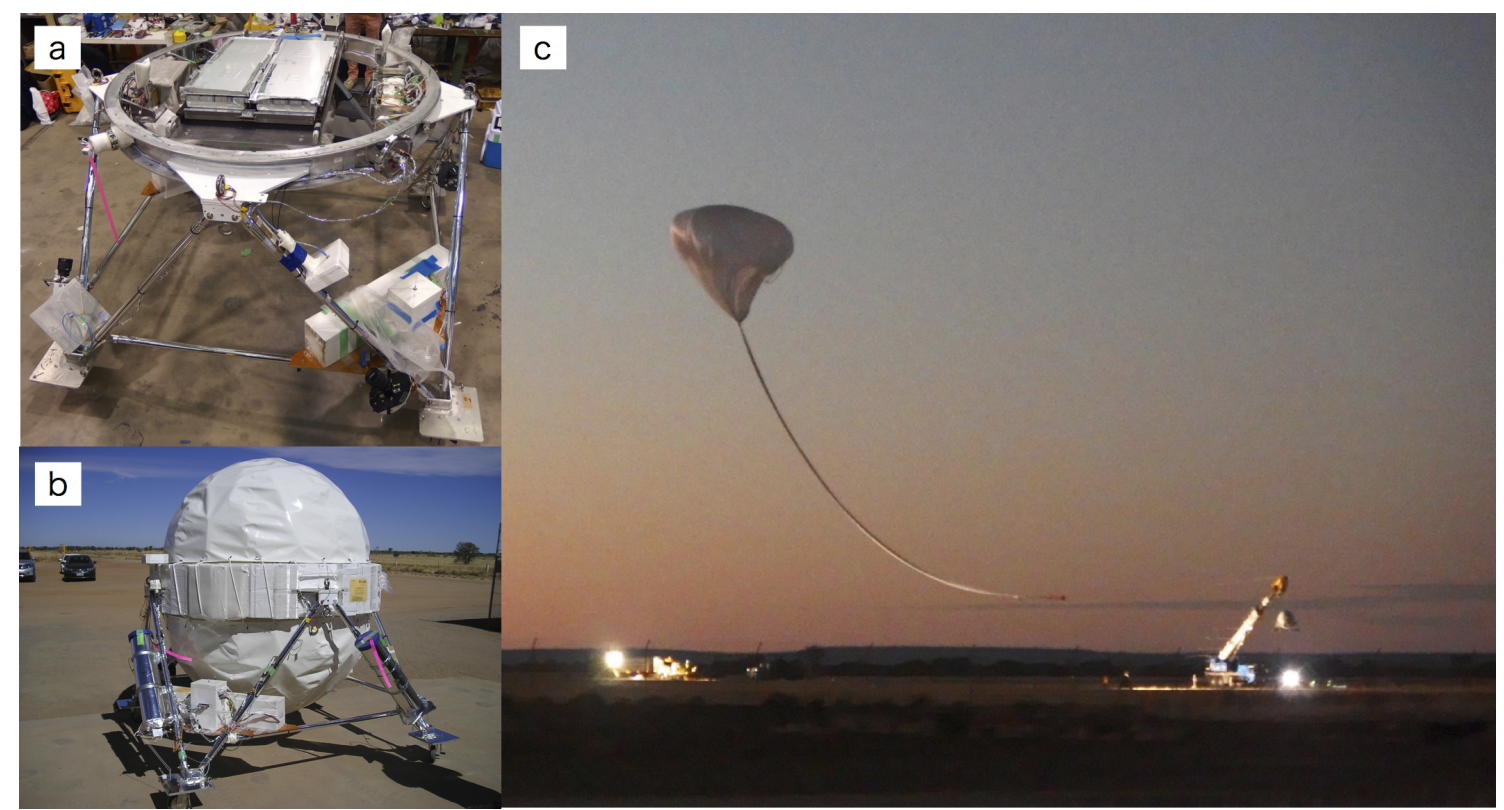

Figure 4: Pictures: a) setup inside the vessel; b) the gondola after pressurizing and insulation; c) a moment of balloon launching.

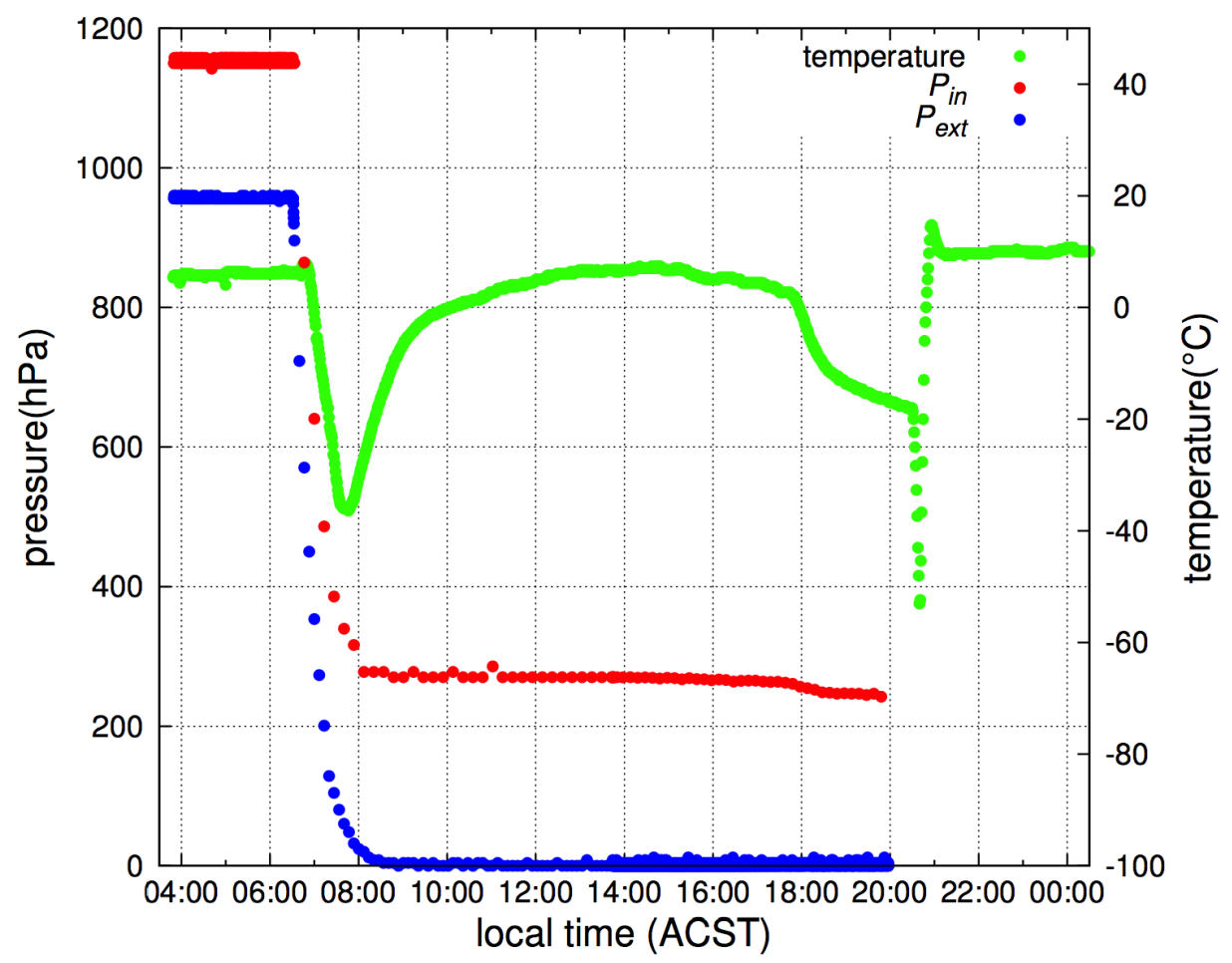

Figure 5: Internal pressure, external pressure of the balloon-style pressure vessel, and temperature at the bottom of the hemispheric shell in the GRAINE 2015 balloon-borne experiment 
realized, and during level flight the pressure around the emulsion telescope was kept above 240 $\mathrm{hPa}$.

All recovered emulsion films were developed at Sydney University, and the readout by an emulsion scanning system [ $[$ ] has been starting at Nagoya University. From now, track data will be analyzed, and the deformation of the chamber in the observation period will be also checked.

\section{Acknowledgment}

We thank Dr. T. Gregory and Dr. J. P. Wefel of ATIC group for the provision for information of their pressure vessel. The scientific balloon(DAIKIKYU) flight opportunity was provided by ISAS, JAXA. This work was supported by JSPS KAKENHI Grant Number 26247039, 26105510, Grant-in-Aid for JSPS Fellows, and "Leadership Development Program for Space Exploration and Research" of Nagoya University program of Leading Graduate Schools.

\section{References}

[1] S. Aoki, et al., [astro-ph.IM/1202.2529].

[2] S. Takahashi, et al., Prog. Theor. Exp. Phys. (2015) 043H01

[3] W. B. Atwood, et al., ApJ 697 (2009) 1071.

[4] S. Takahashi,et al., Nucl. Instr. and Meth. A 620 (2010) 192.

[5] H. Rokujo,et al., Nucl. Instr. and Meth. A 701 (2013) 127.

[6] N. Agafonova, et al., New Journal of Physics 14.1 (2012): 013026.

[7] P. L. Nolan, et al., ApJS 199 (2012) 31.

[8] T. G. Guzik, et al., Adv. Space Res. 33 (2004) 1763.

[9] S. Takahashi, et al., PoS (ICRC2015) 970

[10] K. Ozaki, et al., PoS (ICRC2015) 1004

[11] H. Rokujo, et al., PoS (ICRC2015) 654 